\title{
Choroid plexus cysts and aneuploidy
}

David Peleg, Jerome Yankowitz

\begin{abstract}
The association of choroid plexus cysts with fetal aneuploidy, particularly trisomy 18, was first noted in 1986. Through the years there have been numerous reports on this subject, but no consensus has been reached with regard to chromosomal risk. In this review, we attempt to summarise published reports on second trimester choroid plexus cysts, with an emphasis on the strengths and weaknesses of each report. Based on these reports, additional malformations are a significant risk factor for aneuploidy and an indication for determination of fetal karyotype. The management of isolated choroid plexus cysts remains controversial.

(f Med Genet 1998;35:554-557)
\end{abstract}

Keywords: choroid plexus cyst; aneuploidy; trisomy 18; trisomy 21

The choroid plexus develops in the lateral and fourth ventricles and is responsible for the formation of cerebrospinal fluid (CSF). The plexus is neuroepithelium covered villi which grow and become lobulated. ${ }^{1}$ After 12 weeks, ultrasound easily shows these hyperechoic areas as the most prominent structure seen in the fetal brain. At 16 to 18 weeks' gestation the choroid plexus usually fills almost the entire lateral ventricles. Later, with involution and growth in the size of ventricles, the relative size of the choroid plexus diminishes. ${ }^{1}$ Cysts may occur in the choroid plexus during the second trimester with maximal growth and entanglement of the villi, resulting in entrapment of CSF.

The first sonographic description of choroid plexus cysts (CPCs) is credited to Chudleigh et $a l^{2}$ in 1984. They were considered benign and transitory until a possible association of these cysts with trisomy 18 was found. ${ }^{3}$

Trisomy 18 (Edwards syndrome) occurs in about $1: 3000$ to $1: 5000$ births. ${ }^{4}$ Congenital heart disease in trisomy 18 is as high as $90 \%$, most commonly VSD. ${ }^{4}$ Growth restriction, craniofacial anomalies, and renal anomalies also occur frequently. The majority of fetuses with trisomy 18 will show either an anatomical or biometric anomaly on ultrasound. Twothirds of those detected in the second trimester will spontaneously die in utero. ${ }^{5}$ Of those liveborn, $90-95 \%$ will succumb within the first year of life. ${ }^{4}$

The purpose of this review is to describe what is known about CPCs and their association with aneuploidy. By pooling world publications, we will attempt to determine the incidence of CPCs and their predictive value for

aneuploidy. Finally, we will discuss what remains controversial and unclear and in need of further study.

\section{Methods}

A Medline search of the English language publications from 1980 to 1997 was performed. All articles discussing the association of choroid plexus cysts and aneuploidy were evaluated. Case reports were excluded.

Articles fell into two general categories: (1) those discussing the incidence of choroid plexus cysts in the general population undergoing ultrasound examination with the resulting outcomes of these patients, and (2) those in which only patients with CPCs are discussed with the resulting outcomes.

Data were collected on the size, laterality, complexity, and disappearance of the CPC, as well as type of aneuploidy, other associated anomalies, and maternal age. Associated anomalies included only those detected prenatally and could either be anatomical (for example, clenched hand, heart defects) or biometric (for example, growth restriction or ventriculomegaly).

All 33 studies described women undergoing ultrasound evaluation between 14 and 24 weeks' gestation. Six of the 33 studies included women with gestational age greater than 27 weeks. ${ }^{6-11}$

\section{Results and discussion}

INCIDENCE OF CHOROID PLEXUS CYSTS

Those studies indicating the total number of scans performed and the number of those scans having a fetus with CPCs are shown in table 1 These data indicate that 1 in $122(0.8 \%)$ fetuses scanned will have choroid plexus cysts (range 1 in 300 to 1 in 27.5).

PERCENTAGE OF FETUSES WITH TRISOMY 18 THAT HAVE CHOROID PLEXUS CYSTS

Those studies analysing a series of trisomy 18 fetuses and indicating the percentage with CPCs during the second trimester ultrasound examinations are shown in table 2 . One in 1.8 $(54.3 \%)$ fetuses with trisomy 18 will have a CPC.

\section{ANEUPLOIDIES SEEN WITH CHOROID PLEXUS} CYSTS

Each paper was reviewed for the various aneuploidies seen in association with CPCs. Of 203 reported abnormal karyotypes, there were 161 $(79.3 \%)$ trisomy $18,27(13.3 \%)$ trisomy 21 including translocation Down syndrome, three $(1.5 \%)$ trisomy 13 , four $(2.0 \%)$ triploidy, two $(1.0 \%) 47, \mathrm{XXY}$, and six (3.0\%) with unusual karyotypes each occurring only once.
Received 19 September 1997 Revised version accepted for publication 23 December 1997 
Table 1 Incidence of choroid plexus cysts and aneuploidy in the presence of isolated CPCs and another anomaly

\begin{tabular}{|c|c|c|c|c|c|c|c|c|}
\hline \multirow[b]{2}{*}{ Ref } & \multirow[b]{2}{*}{ Author } & \multirow[b]{2}{*}{ Year } & \multicolumn{2}{|c|}{ Incidence of CPCs } & \multicolumn{4}{|c|}{ Incidence of aneuploidy with } \\
\hline & & & $\begin{array}{l}\text { In population } \\
\text { (No/total) }\end{array}$ & $\%$ & $\begin{array}{l}\text { Isolated CPC } \\
\text { (No/total) }\end{array}$ & $\%$ & $\begin{array}{l}\text { CPC + other anomalies } \\
\text { (No/total) }\end{array}$ & $\%$ \\
\hline 12 & Achiron & 1991 & $30 / 5400$ & 0.6 & $1 / 29$ & 3.5 & $1 / 1$ & 100.0 \\
\hline 13 & Benacerraf & 1989 & - & - & $0 / 38$ & 0.0 & - & - \\
\hline 14 & Camurri & 1989 & $10 / 3000$ & 0.3 & $0 / 9$ & 0.0 & $1 / 1$ & 100.0 \\
\hline 15 & Chan & 1989 & $13 / 513$ & 2.5 & $0 / 13$ & 0.0 & - & - \\
\hline 16 & Chinn & 1991 & $38 / 1045$ & 3.6 & $0 / 36$ & 0.0 & $1 / 2$ & 50.0 \\
\hline 6 & Chitkara & 1988 & $41 / 6288$ & 0.7 & $0 / 38$ & 0.0 & $1 / 3$ & 33.3 \\
\hline 17 & Chitty & 1993 & - & - & $2 / 346$ & 0.6 & $7 / 56$ & 12.5 \\
\hline 2 & Chudleigh & 1984 & - & - & $0 / 5$ & 0.0 & - & - \\
\hline 18 & Clark & 1988 & $5 / 2820$ & 0.2 & $0 / 5$ & 0.0 & - & - \\
\hline 19 & DeRoo & 1988 & $17 / 2084$ & 0.8 & $0 / 17$ & 0.0 & - & - \\
\hline 20 & Gabrielli & 1989 & $21 / 933$ & 2.3 & $0 / 60$ & 0.0 & $4 / 5$ & 80.0 \\
\hline 7 & Gray & 1996 & $208 / 18861$ & 1.1 & $0 / 192$ & 0.0 & $7 / 26$ & 26.9 \\
\hline 8 & Gross & 1995 & - & - & $1 / 74$ & 1.4 & $2 / 6$ & 33.3 \\
\hline 21 & Gupta & 1994 & $595 / 151000$ & 0.4 & $1 / 548$ & 0.2 & $12 / 47$ & 25.5 \\
\hline 22 & Hertzberg & 1989 & - & - & $0 / 29$ & 0.0 & $0 / 2$ & 0.0 \\
\hline 23 & Howard & 1992 & $51 / 4765$ & 1.1 & $1 / 49$ & 2.0 & $0 / 2$ & 0.0 \\
\hline 24 & Kupferminc & 1994 & $102 / 9100$ & 1.1 & $4 / 98$ & 4.1 & $3 / 4$ & 75.0 \\
\hline 9 & Nadel & 1992 & - & - & $0 / 220$ & 0.0 & $12 / 14$ & 85.7 \\
\hline 3 & Nicolaides & 1986 & - & - & $0 / 1$ & 0.0 & $3 / 4$ & 75.0 \\
\hline 10 & Nicolaides & 1992 & - & - & $1 / 49$ & 2.0 & $33 / 72$ & 45.8 \\
\hline 25 & Oettinger & 1993 & - & - & $0 / 12$ & 0.0 & $2 / 2$ & 100.0 \\
\hline 26 & Ostlere & 1990 & $100 / 11700$ & 0.9 & $0 / 91$ & 0.0 & $3 / 9$ & 33.3 \\
\hline 27 & Perpignano & 1992 & $87 / 3764$ & 2.3 & $5 / 86$ & 5.8 & $1 / 1$ & 100.0 \\
\hline 28 & Platt & 1991 & $71 / 7350$ & 1.0 & $0 / 67$ & 0.0 & $4 / 4$ & 100.0 \\
\hline 29 & Porto & 1993 & $63 / 3247$ & 1.9 & $2 / 59$ & 3.4 & $4 / 4$ & 100.0 \\
\hline 30 & Reinsch & 1997 & $301 / 16059$ & 1.9 & $0 / 263$ & 0.0 & $3 / 38$ & 7.9 \\
\hline 31 & Rickets & 1987 & - & - & $1 / 4$ & 25.0 & - & - \\
\hline 32 & Shields & 1996 & - & - & $7 / 274$ & 2.6 & $9 / 11$ & 81.8 \\
\hline 33 & Snijders & 1994 & $387 / 17583$ & 2.2 & $2 / 277$ & 0.7 & $43 / 110$ & 39.1 \\
\hline 11 & Thorpe-Beeston & 1990 & - & - & $0 / 49$ & 0.0 & $20 / 34$ & 58.8 \\
\hline 34 & Twining & 1991 & $19 / 4541$ & 0.4 & $0 / 16$ & 0.0 & $2 / 3$ & 66.7 \\
\hline 35 & Walkinshaw & 1994 & $163 / 15565$ & 1.1 & $5 / 151$ & 3.3 & $0 / 12$ & 0.0 \\
\hline 36 & Zerres & 1992 & $25 / 823$ & 3.0 & $0 / 14$ & 0.0 & $5 / 11$ & 45.5 \\
\hline & Total & & $2347 / 286441$ & 0.8 & $33 / 3219$ & 1.0 & $183 / 484$ & $\begin{array}{l}37.8 \\
1 \text { in } 2.6\end{array}$ \\
\hline
\end{tabular}

RISK OF ANEUPLOIDY WITH ISOLATED CHOROID PLEXUS CYSTS

Studies discussing the risk of aneuploidy in association with isolated CPCs are shown in table 1 . One in $98(1.0 \%)$ fetuses with an isolated CPC will have aneuploidy (range 0 to 1 in 4 ).

RISK OF ANEUPLOIDY WITH ADDITIONAL ANOMALIES

Studies listing the risk of aneuploidy in association with CPCs with at least one additional anomaly are shown in table 1 . One in 2.6 $(37.8 \%)$ fetuses with CPCs and an additional anomaly will have aneuploidy (range 0 to 1 in 1).

SIZE, LATERALITY, MULTIPLICITY, AND COMPLEXITY

Analysis of the data regarding size of CPCs is hampered by the different methods of reporting. For example, some papers listed a range size (minimum/maximum), some a mean and

Table 2 Incidence of CPCs seen by ultrasound evaluation in the 2 nd trimester in fetuses with trisomy 18

\begin{tabular}{llllll}
\hline Ref & Author & fournal & No of trisomy 18 & No of CPC & $\%$ \\
\hline 12 & Achiron & Obstet Gynecol 1991 & 5 & 5 & 100.0 \\
13 & Benaceraff & Am F Obstet Gynecol 1990 & 17 & 5 & 29.4 \\
37 & Bundy & f Ultrasound Med 1986 & 7 & 1 & 14.3 \\
15 & Chan & Obstet Gynecol 1989 & 0 & 2 & 0.00 \\
16 & Chinn & f Ultrasound Med 1991 & 0 & 2 & 0.00 \\
6 & Chitkara & Obstet Gynecol 1988 & 5 & 1 & 20.0 \\
38 & Fitzsimmons & Obstet Gynecol 1989 & 14 & 10 & 71.4 \\
7 & Gray & Prenat Diagn 1996 & 16 & 7 & 43.8 \\
39 & Nyberg & F Ultrasound Med 1993 & 29 & 11 & 37.9 \\
33 & Snijders & Prenat Diagn 1994 & 58 & 38 & 65.5 \\
& Total & & 151 & 82 & 54.3 \\
& & & & 1 in 1.8 \\
\hline
\end{tabular}

standard deviation, and some a minimum below which the cysts were not considered to be significant. Overall, the range of CPCs reported in euploid fetuses was $1 \mathrm{~mm}$ to 21 $\mathrm{mm}$ and $3 \mathrm{~mm}$ to $20 \mathrm{~mm}$ in aneuploid fetuses. A total of 725 (50.5\%) of the reported cysts were unilateral and $710(49.5 \%)$ were bilateral in the euploid fetuses, while in the aneuploid fetuses there were $30(41.1 \%)$ unilateral and 43 $(58.9 \%)$ bilateral cysts $(p=0.147)$. Finally, there was no correlation between either multiplicity, multilocular, or complexity of the CPCs and aneuploidy.

\section{DISAPPEARANCE}

Most CPCs disappear spontaneously during gestation, usually during the second trimester, as first described by Chudleigh et al. ${ }^{2}$ This involution process appears to be part of the natural history of these cysts and has been described at the histological level. ${ }^{1}$ However, ultrasound examination of the head of normal newborns has shown that up to $3 \%$ of normal neonates will have a small, unilateral CPC. ${ }^{40}$ Disappearance of the cysts occurs both in euploid and aneuploid fetuses. There are a number of examples of CPCs in normal fetuses that persist until birth. ${ }^{11}{ }^{19}$ On the other hand, there are examples of cysts in aneuploid fetuses that disappear early. ${ }^{26}{ }^{27} 41$ There is no evidence that the time or lack of disappearance is related to the risk of aneuploidy.

MATERNAL AGE

Maternal age is related directly to the risk of aneuploidy. This is especially true for the trisomies and some sex chromosome aberrations. ${ }^{42}$ 
Table 3 Risk of trisomy 18 with relation to maternal age, CPCs, and additional anomalies

\begin{tabular}{lll}
\hline Maternal age $(y)$ & Isolated CPCs & $C P C+$ additional anomaly \\
\hline $20-24$ & 1 in 2950 & 1 in 225 \\
$25-29$ & 1 in 2300 & 1 in 175 \\
$30-34$ & 1 in 1300 & 1 in 100 \\
$35-39$ & 1 in 470 & 1 in 35 \\
$40-44$ & 1 in 100 & 1 in 10
\end{tabular}

Adapted from ref 33 with permission.

Age specific rates are available. The risk of trisomy 21 and trisomy 18 increases with maternal age with the former being five to seven times more prevalent. For example, at second trimester amniocentesis, a woman aged 35 has a 1 in 263 risk for trisomy 21 and a 1 in 2000 risk for trisomy $18 .^{42}$ If one assumes that CPCs occur in fetuses with trisomy 18 at the same frequency regardless of maternal age, then the incidence of CPCs should increase as maternal age increases.

Unfortunately, maternal age was not consistently reported. Several reports have shown that CPCs in an otherwise normal fetus occur in women of all maternal ages. ${ }^{219} 242933$ One group reporting on 16 women with CPCs and aneuploidy found no difference between their maternal age (mean 29.8 years, SD 8.1) and those with CPCs and normal karyotype (30.6 years, SD 6.2). ${ }^{32}$ In the same report the mean maternal age of the seven women with isolated CPCs and aneuploidy was 18.9 years (SD 2.3), while for the nine fetuses with CPCs and another anomaly, it was 20.4 years (SD 3.7). In another report ${ }^{7}$ there was no difference in mean maternal age between those mothers with fetuses with CPCs and normal karyotype (31 years), CPCs with normal karyotype but with other anomalies ( 31 years), and those with CPCs and trisomy 18 (31 years). However, given the diversity of the reports, it is not possible to do statistical comparisons.

One study was able to show that in those fetuses with CPCs $(n=387)$, the incidence of trisomy 18 was significantly associated with maternal age. ${ }^{33}$ Risk estimates for trisomy 18 were constructed based on the assumptions that (1) the risk of trisomy 18 increases with maternal age; (2) the incidence of CPCs is $1 \%$; (3) $50 \%$ of fetuses with trisomy 18 will have CPCs at mid gestation; and (4) the risk of trisomy 18 increases when additional fetal anomalies are found (table 3 ).

Table 4 Age specific risks of trisomy 18 with isolated CPC and normal maternal triple screen

\begin{tabular}{lll}
\hline Maternal age & Isolated CPC & $\begin{array}{l}\text { Isolated CPC }+ \text { normal } \\
\text { maternal triple screen }\end{array}$ \\
\hline 30 & 1 in 432 & 1 in 1574 \\
31 & 1 in 378 & 1 in 940 \\
32 & 1 in 324 & 1 in 806 \\
33 & 1 in 273 & 1 in 679 \\
34 & 1 in 225 & 1 in 560 \\
35 & 1 in 183 & 1 in 454 \\
36 & 1 in 146 & 1 in 363 \\
37 & 1 in 115 & 1 in 287 \\
38 & 1 in 92 & 1 in 223 \\
39 & 1 in 70 & 1 in 173 \\
40 & 1 in 54 & 1 in 133 \\
41 & 1 in 42 & 1 in 102 \\
42 & 1 in 32 & 1 in 78
\end{tabular}

Adapted from ref 43 with permission.
Addressing the question similarly, Gratton et $a l^{13}$ calculated age specific risks using the assumptions that (1) $30 \%$ of fetuses with trisomy 18 will have CPCs, (2) $80 \%$ of fetuses with trisomy 18 will have additional ultrasonographic anomalies, and (3) maternal triple screen detects $60 \%$ of fetuses with trisomy 18 independent of CPC status. Their opinion was that it is unlikely that ultrasonographic detection of CPCs and maternal serum triple screen identify the same fetuses with trisomy 18 , an assumption unsupported as yet by data. Their results are shown in table 4 . Using their calculations, amniocentesis would be recommended to women aged 33 and above for those with isolated CPCs, and aged 37 and above if the maternal serum triple screen were also normal.

\section{Recommendations}

Twenty-three reports gave recommendations. All regarded CPCs as an indication for a detailed anomaly scan. In the face of CPCs and another anomaly, all suggested fetal karyotyping. When the CPC was isolated, 11 authors said they would not recommend invasive testing, ${ }^{279} 1116172123253033$ four said they would not unless the cysts appeared unusual (large, bilateral, complex, or persistent), ${ }^{622} 2634$ and nine said they would in all cases. ${ }^{3} 12242729323530$

\section{Other parameters}

There are other parameters that probably affect the detection of CPCs and the calculated risk of aneuploidy. For example, ultrasonography has become more refined, with better machines and more experienced operators. These two factors probably would increase detection of both CPCs and additional anomalies. On the other hand, not all sonographers search for the same group of anomalies (for example, clenched hands).

The statistical analysis performed in table 1 is based on the assumption that the various reports mentioned are comparable. The differences in population, machines, and sonographers is certainly confounding. However, although the articles discussing the incidence of CPC detection were published between 1988 and 1997 (table 1), an increase in trend cannot be found.

Finally, maternal serum triple screen can reportedly detect up to $60 \%$ of trisomy 18 in the absence of an open defect. ${ }^{44}$ There have not been any studies exploring the combination of CPCs on ultrasound and a positive maternal serum triple screen for detection of aneuploidy.

\section{Summary}

CPCs should be considered an indication to search for other anomalies. Although the incidence is 1 in 122 pregnancies, fetuses with trisomy 18 display CPCs at least $50 \%$ of the time. The presence of associated sonographic anomalies, whether biometric or anatomical, increases the risk of aneuploidy by over 35 times. Maternal age also correlates with aneuploidy. Trisomy 18 and trisomy 21 are similar in that by limiting invasive testing to 
above a certain maternal age (for example, 35 years), many cases with chromosomal abnormalities will be missed.

Isolated CPCs have an overall detection rate for aneuploidy of 1 in 98, meaning a false positive rate of about $99 \%$. Controversy remains whether an isolated CPC is an indication for invasive testing. We suggest that in the presence of another risk factor, whether it be an abnormal maternal serum triple screen, a previous child with aneuploidy, advanced maternal age, or additional detected anomaly, the patient should be made aware of the higher risk of aneuploidy and the benefit of prenatal testing. At present, with an isolated CPC, we attempt to counsel the patient in a nondirective fashion similar to those with a trisomy 18 pattern on maternal serum screening. ${ }^{45}$ The mother is told that studies indicate that the risk of aneuploidy is about 1 in 100, although her age influences this rate. All patients are offered amniocentesis for definitive diagnosis. Serum triple screen should be obtained if not available and the mother is less than 20 weeks' gestation. For those electing to continue the pregnancy without invasive testing, we do suggest serial fundal height examinations and a repeat ultrasound for growth and anomalies before 24 weeks to allow the patient to reconsider amniocentesis.

1 Kennedy KA, Carey JC. Choroid plexus cysts: significance and current management practices. Semin Ultrasound, CT and MRI 1993;14:23-30.

2 Chudleigh P, Pearce JM, Campbell S. The prenatal diagnosis of transient cysts of the fetal choroid plexus. Prenat Diagn $1984 ; 4: 135-7$.

3 Nicolaides KH, Rodeck CH, Gosden CM. Rapid karyotyping in non-lethal fetal malformations. Lancet 1986; i:283-7. ing in non-lethal fetal malformations. Lancet 1986;i:283-7. ders. In: Callen PW, ed. Ultrasonography in obstetrics and ders. In: Callen PW, ed. Ultrasonography in obst

gynecology. Philadelphia: Saunders, 1994:41-2.
5 Hook EB, Topol BB, Cross PK. The natural history of cytogenetically abnormal fetuses detected in midtrimester amniocentesis which are not terminated electively: new data and estimates of the excess and relative risk of later fetal death associated with $47,+21$ and some other abnormal karyotypes. Am 7 Hum Genet 1989;45:855-61.

6 Chitkara U, Cogswell C, Norton K, Wilkins IA, Mehalek K, Berkowitz RL. Choroid plexus cysts in the fetus: a benign anatomic variant or pathologic entity? Report of 41 cases and review of the literature. Obstet Gynecol 1988;72:185-9.

7 Gray DL, Winborn RC, Suessen TL, Crane JP. Is genetic amniocentesis warranted when isolated choroid plexus cysts are found? Prenat Diagn 1996;16:983-90.

8 Gross SJ, Shulman LP, Tolley EA, et al. Isolated fetal choroid plexus cysts and trisomy 18: a review and choroid plexus cysts and trisomy 18: a review

9 Nadel AS, Bromley BS, Frigoletto FD Jr, Estroff JA, Benacerraf BR. Isolated choroid plexus cysts in the seconderraf BR. Isolated choroid plexus cysts in the second-
trimester fetus: is amniocentesis really indicated? Radiology trimester fetus: is

10 Nicolaides KH, Snijders RJM, Gosden CM, Berry C, Campbell S. Ultrasonographically detectable markers of fetal chromosomal abnormalities. Lancet 1992;340:704-7.

11 Thorpe-Beeston JG, Gosden CM, Nicolaides KH. Choroid plexus cysts and chromosomal defects. $\mathrm{Br} \mathcal{F}$ Radiol 1990;63:783-6.

12 Achiron R, Barkai G, Katznelson MBM, Mashiach S. Fetal lateral ventricle choroid plexus cysts: the dilemma of amniocentesis. Obstet Gynecol 1991;78:815-18.

13 Benacerraf BR, Laboda LA. Cyst of the fetal choroid plexus: a normal variant? Am ₹ Obstet Gynecol 1989;160:319-21.

14 Camurri L, Ventura A. Prospective study on trisomy 18 and fetal choroid plexus cysts. Prenat Diagn 1989;9:742.

15 Chan L, Hixson JL, Laifer SA, Marchese SG, Martin JG, Hill LM. A sonographic and karyotypic study of secondHill LM. A sonographic and karyotypic study of second-
trimester fetal choroid plexus cysts. Obstet Gynecol 1989;73: 703-6.
16 Chinn DH, Miller EI, Worthy LM, Towers CV. Sonographically detected fetal choroid plexus cysts. $\mathcal{f}$ Ultrasound Med 1991;10:255-8.

17 Chitty LS, Chudleigh T. Choroid plexus cysts-when to karyotype? Br Med Ultrasound Soc Bul 1993;1:40-1.

18 Clark SL, DeVore GR, Sabey PL. Prenatal diagnosis of cysts of the fetal choroid plexus. Obstet Gynecol 1988;72:585-7.

19 DeRoo TR, Harris RD, Sargent SK, Denholm TA, Crow HC. Fetal choroid plexus cysts: prevalence, clinical significance, and sonographic appearance. $A F R$ 1988;151:117981 .

20 Gabrielli S, Reece EA, Pilu G, et al. The clinical significance of prenatally diagnosed choroid plexus cysts. Am $\mathcal{F}$ Obstet Gynecol 1989;160:1207-10.

21 Gupta JK, Cave M, Lilford RJ, et al. Clinical significance of fetal choroid plexus cysts. Lancet 1995;346:724-9.

22 Hertzberg BS, Kay HH, Bowie JD. Fetal choroid plexus lesions. Relationship of antenatal sonographic appearance to clinical outcome. F Ultrasound Med 1989;8:77-82.

23 Howard RJ, Tuck SM, Long J, Thomas VA. The significance of choroid plexus cysts in fetuses at 18-20 weeks. An indication for amniocentesis? Prenat Diagn 1992;12:685-8.

24 Kupferminc MJ, Tamura RK, Sabbagha RE, Parilla BV, Cohen LS, Pergament E. Isolated choroid plexus cyst(s): an indication for amniocentesis. Am $\mathcal{F}$ Obstet Gynecol 1994; 171:1068-71.

25 Oettinger $\mathbf{M}$, Odeh $\mathbf{M}$, Korenblum $\mathbf{R}$, Markovits J. Antenatal diagnosis of choroid plexus cyst: suggested management. Obstet Gynecol Surv 1993;48:635-9.

26 Ostlere SJ, Irving HC, Lilford RJ. Fetal choroid plexus cysts: a report of 100 cases. Radiology 1990;175:753-5.

27 Perpignano MC, Cohen HL, Klein VR, et al. Fetal choroid plexus cysts: beware the smaller cyst. Radiology 1992;182: 715-17.

28 Platt LD, Carison DE, Medearis AL, Walla CA. Fetal choroid plexus cysts in the second trimester of pregnancy: a cause for concern. Am F Obstet Gynecol 1991;164:1652-6.

29 Porto M, Murata Y, Warneke LA, Keegan KA Jr. Fetal choroid plexus cysts: an independent risk factor for choroid plexus cysts: an independent risk factor for
chromosomal anomalies. 7 Clin Ultrasound 1993;21:103-8.

30 Reinsch RC. Choroid plexus cysts-association with trisomy: prospective review of 16,059 patients. Am $\mathcal{F}$ Obstet Gynecol 1997;176:1381-3

31 Ricketts NEM, Lowe EM, Patel NB. Prenatal diagnosis of choroid plexus cysts. Lancet 1987;i:213-14.

32 Shields LE, Uhrich SB, Easterling TR, Cyr DR, Mack LA. Isolated fetal choroid plexus cysts and karyotype analysis: is it necessary? $\mathcal{F}$ Ultrasound Med 1996;15:389-94.

33 Snijders RJM, Shawa L, Nicolaides KH. Fetal choroid plexus cysts and trisomy 18: assessment of risk based on plexus cysts and trisomy 18: assessment of risk based on 1994;14:1119-27.

34 Twining P, Zuccollo J, Clewes J, Swallow J. Fetal choroid plexus cysts: a prospective study and review of the literature. Br $\mathcal{F}$ Radiol 1991;64:98-102.

35 Walkinshaw S, Pilling D, Spriggs A. Isolated choroid plexus cysts - the need for routine offer of karyotyping. Prenat Diagn 1994;14:663-7.

36 Zerres A, Schüler, Gembruch U, Bald R, Hansmann M, Schwanitz G. Chromosomal findings in fetuses with prenatally diagnosed cysts of the choroid plexus. Hum Genet 1992;89:301-4.

37 Bundy AL, Saltzman DH, Pober B, Fine C, Emerson D, Doubilet PM. Antenatal sonographic findings in trisomy 18. ₹ Ultrasound Med 1986;5:361-4

38 Fitzsimmons J, Wilson D, Pascoe-Mason J, Shaw CM, Cyr DR, Mack LA. Choroid plexus cysts in fetuses with trisomy 18. Obstet Gynecol 1989;73:257-60.

39 Nyberg DA, Kramer D, Resta RG, et al. Prenatal sonographic findings of trisomy 18 . Review of 47 cases. $\mathcal{F}$ Ultrasound Med 1993;12:103-13.

40 Riebel T, Nasir R, Weber K. Choroid plexus cysts: a normal finding on ultrasound. Pediatr Radiol 1992;22:410-12.

41 Montemagno R, Soothill PW, Scarcelli M, Rodeck CH. Disappearance of fetal choroid plexus cysts during the second trimester in cases of chromosomal abnormality. $\mathrm{BrF}$ Obstet Gynecol 1995;102:752-3.

42 Ferguson-Smith MA, Yates JRW. Maternal age specific rates for chromosome aberrations and factors influencing them: report of a collaborative European study on 52,965 amniocenteses. Prenat Diagn 1984;4:5-44.

43 Gratton RJ, Hogge WA, Aston CE. Choroid plexus cysts and trisomy 18: risk modification based on maternal age and multiple-marker screening. Am $\mathcal{F}$ Obstet Gynecol 1996; 175:1493-7.

44 Palomaki GE, Haddow JE, Knight GJ, et al. Risk-based prenatal screening for trisomy 18 using alpha-fetoprotein unconjugated oestriol and human chorionic gonadotropin. Prenat Diagn 1995;15:713-23.

45 Yankowitz J, Fulton A, Williamson R, Grant S, Budelier Yankowitz J, Fulton A, Williamson R, Grant S, Budelier screening for trisomy 18. Am $\mathcal{f}$ Obstet Gynecol (in press). 